\title{
The Development of Fundamental Movement Skills by Children Aged Six to Nine
}

\author{
Shu-Jung Lin ${ }^{1, *}$, Shu-Chu Yang ${ }^{2}$ \\ ${ }^{1}$ Department of Early Childhood Educare, Chung Chou University of Science and Technology, Taiwan \\ ${ }^{2}$ Department of Early Childhood Education, National ChiaYi University, Taiwan
}

Copyright $(\mathcal{C} 2015$ by authors, all rights reserved. Authors agree that this article remains permanently open access under the terms of the Creative Commons Attribution License 4.0 International License

\begin{abstract}
The main purpose of the present study is to elucidate any differences which may exist in the FMSs of children between the ages of six and nine. Purposive sampling was used to recruit a total of 485 participants (244 boys and 241 girls) in Chiayi City and Chiayi County. All of the participants were between the ages of six and nine and had no disabilities or major health problems. Of these, 92 were between the ages of six and seven; 197 were between the ages of seven and eight; and 196 were between the ages of eight and nine. The average age was seven years and eight months. The main research tool used in this study was the Test of Gross Motor Development-2 (TGMD-2). There was a significant difference in both overall object control skills $(t=9.08, p<.001)$ and overall performance $(t$ $=5.45, p<.001)$, with the boys performing better than the girls in both overall object control skills $(M=31.48>M$ $=20.29)$ and overall performance $(M=56.84>M=$ 52.47). Significant differences were also found for overall locomotor skills $(F=12.29, p<.001)$, overall object control skills $(F=12.81, p<.001)$, and overall FMSs $(F=$ $20.44, p<.001)$. For locomotor skills the Scheffé post hoc test revealed that those aged eight and nine performed better than those aged between six and eight, and that those aged between seven and eight performed better than those aged between six and seven. For object control skills and overall FMSs the Scheffé post hoc test revealed that those aged between eight and nine performed better than those aged between six and eight. Thus it would be desirable for physical education teachers at elementary schools to have girls participate in a variety of ball games, and also to encourage girls to engage in simple catching, throwing, and dribbling activities after school. In sum, schools need to provide a variety of movement activities which students find interesting, and also encourage students to participate in sports after class and outside of school.
\end{abstract}

Keywords Locomotor Skills, Objective Control Skills, Fundamental Movement Skills

\section{Introduction}

Beginning from birth, an infant gradually learns how to use its muscles so as to control its movements and manipulate objects, a developmental process which proceeds in a definite direction and follows a predictable order. As the child matures, the acquisition of each new complex movement skill relies on previously acquired movement skills. Furthermore, physical, cognitive, emotional, and social development varies over the course of a lifetime. Physical development includes changes in stature, proportions, appearance, health, and movement skills, each stage of which has a certain amount of plasticity [1].

According to the Sport Administration of Taiwan's Ministry of Education [2], children between the ages of three and eight are highly eager to learn new skills and have little fear of injury or failure. Thus it is stressed that this early stage of growth should focus on the development of fundamental movement skills (FMS), and that after the age of eight the focus should shift to the development of more advanced movement skills. Similarly, Weikart [3] has pointed out that first and second graders need to acquire a wide variety of physical skills, including such object control skills as throwing, kicking, and catching a ball, and such movement skills as walking, running, and hopping. Moreover, the successful development of FMSs is not only essential to the acquisition of complex movement skills, but also promotes muscle coordination and assists in the development of interpersonal, cognitive, and emotional skills [4]. FMS can be divided into locomotor skills (LS) and object-control skills (OCS) [8].

Additionally, Ulrich and Sanford [5] point out that a child who is less skilled than most of his or her peers will generally be chosen last to participate in group games during recess and after-school activities. The consequence of consistently being selected last or not at all is likely to have a negative impact on a child's physical self-concept and motivation to be active.

Studies on the development of FMSs conducted in both Taiwan and elsewhere have yielded different results. Some 
$[6,7]$ have found no difference between the locomotor skills of boys and girls, while others $[8,9,10]$ have found girls to be superior. For example, Yang et al. [10] found girls to perform better than boys in such skills as galloping, hopping, horizontal jumping, and sliding. Further, Hardy et al. [8] also found girls to perform better than boys in hopping. Conversely, a number of studies $[6,7,8,9,11$,] have found that boys perform significantly better in object control skills. For example, Hardy et al. [8] found that boys were better than girls at striking a stationary ball, kicking, and overhand throwing, but found no difference in catching.

As for age differences, Li [7] found that FMSs steadily develop between the ages of three and ten. Similarly, Chow and Louie [12] found that locomotor and object control skills increase steadily and equally with age.

In light of the importance of FMSs in their own right, as well as the important role they play in various other key areas of development, how FMSs develop during childhood is a critical area of research. Thus the main purpose of the present study is to elucidate any differences which may exist in the FMSs of children between the ages of six and nine.

\section{Methodology}

\subsection{Participants}

Purposive sampling was used to recruit a total of 485 participants (244 boys and 241 girls) in Chiayi City and Chiayi County. All of the participants were between the ages of six and nine and had no disabilities or major health problems. Of these, 92 were between the ages of six and seven; 197 were between the ages of seven and eight; and 196 were between the ages of eight and nine. The average age was seven years and eight months.

\subsection{Instrumentation}

The main research tool used in this study was the Test of Gross Motor Development-2 (TGMD-2) developed by Ulrich and Sanford [5]. The TGMD-2 measures both locomotor skills (running, galloping, hopping, leaping, horizontal jumping, and sliding) and object control skills (striking a stationary ball, stationary dribbling, catching, kicking, throwing, and rolling). Each gross motor skill includes several behavior components that serve as performance criteria. In general, if the child performs a behavior component correctly, the examiner marks a 1; if the child does not perform a behavior component correctly, the examiner marks a 0 [5]. The materials needed for administering the TGMD-2 are an 8 "-10" playground ball, a 4" lightweight ball, a basketball, a tennis ball, a soccer ball, a softball, a 4"-5" square beanbag, tape, two traffic cones, a plastic bat, and a batting tee.

\subsection{Procedures}

Prior to testing, we contacted the principal of each participating elementary school by telephone and explained the purpose of the research and how it would be conducted. We also contacted the teachers who agreed to have their class participate in the study, and explained how much time would be required and the assistance they would need to provide. The participating teachers were asked to distribute and collect parental consent forms which included permission to film the performance of each participant.

Each participant's performance was evaluated by playing the video recording at a slow speed using Windows Media. A total of six research assistants were trained to carry out the performance evaluation, four of whom had a reliability level of 0.8 or higher, and were thus selected to carry out the actual evaluation. The four evaluators were divided evenly into two teams, and each performance was independently evaluated by both team members, with any discrepancies being re-evaluated so as to insure consistency.

\subsection{Data Analysis}

The raw data was analyzed using means and standard deviation. A t-test and one-way analysis of variance were used to compare the locomotor skills, object control skills, and FMSs of the participants with respect to age and gender.

\section{Results}

\subsection{Differences in locomotor Skills, Object Control Skills, and Overall Performance in Terms of Gender}

As shown in Table 1, no significant difference was found for any of the six locomotor skills, nor for overall performance. However, there was a significant difference in four of the six object control skills: striking a stationary ball $(t=7.99, p<.001)$; stationary dribble $(t=2.32, p<.05)$; throwing $(t=6.66, p<.001)$; and rolling $(t=4.32, p<.001)$. In each of these four items the boys outperformed the girls: striking a stationary ball $(M=6.48>M=4.80)$; stationary dribbling $(M=4.62>M=4.19)$; throwing $(M=5.80>$ $M=4.44)$; and rolling $(M=4.38>M=3.57)$. While there was no significant difference in kicking, this was the object control skill in which both boys and girls had the best performance.

In addition, there was a significant difference in both overall object control skills $(t=9.08, p<.001)$ and overall performance $(t=5.45, p<.001)$, with the boys performing better than the girls in both overall object control skills $(M$ $=31.48>M=20.29)$ and overall performance $(M=$ $56.84>M=52.47)$. 
Table 1. Differences in locomotor skills, object control skills, and overall performance in terms of gender

\begin{tabular}{|c|c|c|c|}
\hline \multirow{2}{*}{ Item } & \multicolumn{2}{|c|}{ Mean score $(M) / \mathrm{SD}$} & \multirow{2}{*}{$t$} \\
\cline { 2 - 3 } & Boys & Girls & \\
\hline Running & $7.06 / 1.17$ & $7.15 / 1.16$ & -.87 \\
\hline Galloping & $3.05 / 1.79$ & $3.20 / 1.84$ & -.89 \\
\hline Hopping & $4.36 / 2.18$ & $4.60 / 2.37$ & -1.17 \\
\hline Leaping & $4.80 / 1.09$ & $4.81 / 1.11$ & -.10 \\
\hline Horizontal jumping & $3.83 / 2.06$ & $3.96 / 2.11$ & -.69 \\
\hline Sliding & $2.25 / 2.64$ & $2.03 / 2.52$ & .96 \\
\hline Locomotor skills & $25.36 / 5.57$ & $25.76 / 5.19$ & -.81 \\
\hline Striking a stationary ball & $6.48 / 2.40$ & $4.80 / 2.21$ & $7.99 * * *$ \\
\hline Stationary dribble & $4.62 / 2.13$ & $4.19 / 2.02$ & $2.32^{*}$ \\
\hline Catching & $3.73 / 1.33$ & $3.51 / 1.38$ & 1.78 \\
\hline Kicking & $6.47 / 1.82$ & $6.21 / 1.63$ & 1.66 \\
\hline Overhand throwing & $5.80 / 2.31$ & $4.44 / 2.19$ & $6.66^{* * *}$ \\
\hline Underhand rolling & $4.38 / 2.11$ & $3.57 / 2.03$ & $4.32^{* * *}$ \\
\hline Object control skills & $31.48 / 5.67$ & $26.71 / 5.88$ & $9.08^{* * *}$ \\
\hline Overall performance & $56.84 / 8.70$ & $52.47 / 8.95$ & $5.45^{* * *}$ \\
\hline
\end{tabular}

Note. boys: $\mathrm{N}=244$; girls: $\mathrm{N}=241$

${ }^{*} p<.05 ; * * * p<.001$

\subsection{Differences in Locomotor Skills, Object Control Skills, and Overall Performance in Terms of Age}

As shown in Table 2, a significant difference was found for four of the six locomotor skills: running, leaping, jumping, and sliding. In running $(F=26.09, p<.001)$ and jumping $(F=10.73, p<.001)$, the Scheffé post hoc test revealed that those aged between seven and nine performed better than those aged between six and seven. In sliding $(F=$ 9.51, $p<.001)$ the Scheffé post hoc test revealed that those aged between eight and nine performed better than those aged between six and eight. However, the Scheffé post hoc test revealed no significant difference for leaping.

Moreover, a significant difference was found for dribbling $(F=5.94, p<.01)$, catching $(F=11.78, p<.001)$, and throwing $(F=12.08, p<.001)$. The Scheffé post hoc test for throwing revealed that those aged eight and nine performed better than those aged between six and eight, and that those aged seven and eight performed better than those aged between six and seven. As for dribbling and catching, the Scheffé post hoc test revealed that those aged eight and nine performed better than those aged between six and eight.

Significant differences were also found for overall locomotor skills $(F=12.29, p<.001)$, overall object control skills $(F=12.81, p<.001)$, and overall FMSs $(F=$ $20.44, p<.001)$. For locomotor skills the Scheffé post hoc test revealed that those aged eight and nine performed better than those aged between six and eight, and that those aged between seven and eight performed better than those aged between six and seven. For object control skills and overall FMSs the Scheffé post hoc test revealed that those aged between eight and nine performed better than those aged between six and eight.

Table 2. Differences in locomotor skills, object control skills, and overall performance in terms of age

\begin{tabular}{|c|c|c|c|c|}
\hline \multirow[b]{2}{*}{ Item } & Mean score & SD & \multirow[b]{2}{*}{$F$} & \multirow[b]{2}{*}{ Post hoc tes } \\
\hline & \multicolumn{2}{|c|}{$\begin{array}{l}\text { A.6-7/B.7-8 } \\
\text { C.8-9/ (age) }\end{array}$} & & \\
\hline Running & $6.57 / 6.95 / 7.51$ & $1.42 / 1.19 / 0.81$ & $26.09 * * *$ & $\mathrm{C}>\mathrm{B}>\mathrm{A}$ \\
\hline Galloping & $2.86 / 3.33 / 3.05$ & $1.92 / 1.90 / 1.65$ & 2.45 & \\
\hline Hopping & $4.89 / 4.34 / 4.43$ & $2.53 / 2.31 / 2.10$ & 1.95 & \\
\hline Leaping & $4.65 / 4.74 / 4.95$ & $1.09 / 1.10 / 1.08$ & $3.11 *$ & $n s$ \\
\hline Horizontal jumping & $3.01 / 4.14 / 4.07$ & $1.81 / 2.10 / 2.09$ & $10.73 * * *$ & B.C $>$ A \\
\hline Sliding & $1.51 / 1.85 / 2.73$ & $2.15 / 2.42 / 2.81$ & $9.51^{* * *}$ & $\mathrm{C}>\mathrm{A} . \mathrm{B}$ \\
\hline Locomotor skills & $23.49 / 25.34 / 26.74$ & $5.41 / 5.12 / 5.32$ & $12.29 * * *$ & $\mathrm{C}>\mathrm{B}>\mathrm{A}$ \\
\hline Striking a stationary ball & $5.80 / 5.47 / 5.74$ & $2.14 / 2.52 / 2.52$ & 0.83 & \\
\hline Stationary dribbling & $4.08 / 4.17 / 4.80$ & $1.95 / 2.04 / 2.14$ & $5.94 * *$ & $\mathrm{C}>\mathrm{A} . \mathrm{B}$ \\
\hline Catching & $3.23 / 3.47 / 3.96$ & $1.44 / 1.32 / 1.29$ & $11.78 * * *$ & $\mathrm{C}>\mathrm{A} . \mathrm{B}$ \\
\hline Kicking & $6.25 / 6.19 / 6.53$ & $1.63 / 1.71 / 1.78$ & 2.08 & \\
\hline Overhand throwing & $4.24 / 5.01 / 5.64$ & $2.35 / 2.40 / 2.16$ & $12.08 * * *$ & $\mathrm{C}>\mathrm{B}>\mathrm{A}$ \\
\hline Underhand rolling & $3.82 / 3.93 / 4.10$ & $2.03 / 2.08 / 2.18$ & 0.63 & \\
\hline Object control skills & $27.41 / 28.25 / 30.77$ & $6.52 / 6.15 / 5.82$ & $12.81 * * *$ & $\mathrm{C}>\mathrm{A} . \mathrm{B}$ \\
\hline Overall performance & $50.90 / 53.59 / 57.52$ & $9.02 / 8.50 / 8.85$ & $20.44 * * *$ & $\mathrm{C}>\mathrm{A} . \mathrm{B}$ \\
\hline
\end{tabular}

Note. $6-7$ years: $\mathrm{N}=92 ; 7-8$ years: $\mathrm{N}=197 ; 8-9$ years: $\mathrm{N}=196$,

${ }^{*} p<.05 ; * * p<.01 ; * * * p<.001$

$n s$ indicates no significant difference in the post hoc comparison. 


\section{Discussion}

In this study it was found that boys and girls aged between six and nine have roughly equal locomotor skills, as has been found by Goodway et al. [6] and Li [7]. It was also found that in the same age group the boys performed better in four out of six object control skills: striking a stationary ball, stationary dribbling, overhand throwing, and underhand rolling. This finding mainly agrees with Hardy et al. [8], except that the boys in their study also performed significantly better in kicking. By contrast, in the present study, of all the object control items, both the boys and the girls were best at kicking, and they were nearly equally good at it.

We also found that the boys had significantly better scores in overall object control skills, as was found in most previous studies $[6,7,8,9,11]$. While $\mathrm{Li}[7]$ asserts that boys tend to develop object control skills more quickly, it's also possible that this difference is largely due to the influence of the role expectations of parents, many of whom consider ball games to be too rough for girls, and therefore tend to discourage their daughters from participating in them. In fact, a number of related studies have found that parents, especially fathers, have a major influence on the sports their children participate in, and that fathers tend to encourage their sons, but not their daughters, to participate in ball games $[13,14]$.

We further found that the locomotor skills of both boys and girls increased with age. As for object control skills and overall development, however, those between the ages of eight and nine performed better than the younger participants, but there was no significant difference between those aged between six and seven and those aged between seven and eight. This may be the result of the emphasis on such activities as stretching exercises, running, and skipping rope in physical education classes for first and second graders at Taiwanese elementary schools. Indeed, Payne and Isaacs [14] assert that the content of physical education classes and how it is taught has an influence on the development of physical skills by children.

Finally, Hu [15] asserts that comprehensive development needs to be planned and systematic. Moreover, Berk [1] contends that each stage of development has a certain degree of plasticity, such that as long as they are provided with a number of suitable activities, children will develop the physical skills they require. Thus it would be desirable for physical education teachers at elementary schools to have girls participate in a variety of ball games, and to encourage girls to engage in simple catching, throwing, and dribbling activities. Class teachers can also arrange a corner that stores various balls supporting students to use in any time. Teachers also can set some tasks for students to challenge, for example, each student dribbles continuously ten times once in a day. In sum, schools need to provide a variety of movement activities which students find interesting, and also encourage students to participate in sports after class and outside of school.

\section{REFERENCES}

[1] Berk, L. E. (2007). Development through the Lifespan $\left(4^{\text {th }}\right.$ edition). Boston, Ma: Allyn \& Bacon.

[2] The Sport Administration of Taiwan's Ministry of Education(2013). Children's exercise program. Retrieved June 30, 2014 from the World Wide

Web:http://www.sa.gov.tw/wSite/ct? $x$ Item $=3733 \&$ ctNode $=3$ $40 \& m p=11$

[3] Weikart, P. S. (1998). Round the circle: Key experiences in movenent for children. Michigan: High/Scope Education Research.

[4] Pang, A. Y., \& Fong, W. Y. (2009) Fundamental motor skill proficiency of Hong Kong children aged 6-9 years. Research in Sports Medicine, 17, 125-144.

[5] Ulrich, D.A., \& Sanford, C. B. (2000) TGMD-2 : test of gross motor development: examiner's manual (2nd ed.). Austin TX: PRO-ED.

[6] Goodway, J. D., Crowe, H., \& Ward, P. (2003) Effect of motor skill instruction on fundamental motor skill development. Adapted Physical Activity Quarterly, 20(3), 298-314.

[7] Li, L. (2009) Children Gross Motor Development from Ages 3 to 10 in Shandong. Journal of Shandong Institute of Physical Education and Sports, 25(4), 47-50.

[8] Hardy, L. L., King, L., Farrell, L., Macniven, R., \& Howlett, S. (2009) Fundamental movement skills among Australiam preschool children. Journal of Science and Medicine in Sport, 13(5), 503-508.

[9] LeGear, M., Greyling, L., Sloan, E., Bell, R. I., Williams, B. L., Naylor, P. J., \& Temple, V. A. (2012) A window of opportunity? Motor skills and perceptions of competence of children in kindergarten. International Journal of Behavior Nutrition and Physical Activity, 9, 29.

[10] Yang, S. C., Lin, S. J., \& Tsai, C. Y.(2014) Comparison of fundamental movement skills among young children with different gender age and BMI. Sports \& Exercise Research, 16(3), 287-296.

[11] Giagazoglou, P., Kabitsis, N., Kokaridas, D., Zaragas, C., Katartzi, E., \& Kabitsis, C. (2011) The movement assessment battery in Greek preschoolers: the impact of age, gender, birth order, and physical activity on motor outcome. Research in Developmental Disabilities, 32, 2577-2582.

[12] Chow, B. C., Louie, L. H. T. (2013). Difference in children's gross motor skills between two types of preschools. Perceptual and Motor Skills, 116, 253-261.

[13] Fagot , B. I., \& Leinbach, M. D. (1989). The young child's gender schema: Environmental input, internal organization. Child Development, 60, 663-672.

[14] Payne, V. G., \& Isaacs, L. D. (2008). Human motor development: A lifespan approach $\left(7^{\text {th }}\right.$ ed.). New York: McGraw-Hill Companies.

[15] Hu, T. M.(2009). The kindergarten physical activity guidelines. Elementary Education, 49(4), 39-43. 